\title{
The development of transport infrastructure development projects
}

\author{
Alisa Sablina, and Svetlana Borodulina* \\ Admiral Makarov State University of Maritime and Inland Shipping, 5/7, Dvinskaya st., St. Petersburg, \\ 198035, Russia
}

\begin{abstract}
In modern conditions, one of the key factors in the economic growth of any territory is an efficiently functioning infrastructure that determines the quality of life of the population and business activity in all sectors of the economy. Transport, which is the most important element of infrastructure, implies the need to constantly improve the quality of services provided to the population in order to form a single economic space on the territory of the country. The article discusses the methods of assessment and selection of transport infrastructure development projects currently used in Russia and abroad. The problems of applying the existing methods have been identified, which requires their refinement and improvement. The article proposes a method for multi-criteria assessment and selection of transport infrastructure development projects. It will contribute to the fastest and most effective achievement of the transport infrastructure development project goals in the regions and in the country as a whole. In addition, a mechanism for calculating the effects of project implementation on related industries has been determined. Methods for assessing the risk of project implementation are proposed. The scheme of the proposed method is presented, which allows monitoring the implementation of the project by checkpoints. The paper also presents an algorithm for multi-criteria assessment and selection of projects, demonstrating the possibility of practical application of the presented developments. The research on the basis of taking into account the interests of all potentially interested parties, solving systemic management problems (the absence of "manual guidance" and the introduction of a well-functioning selection mechanism), the clarity and transparency of the mechanisms developed allowed obtaining an adequate method and make the considered and selected project demanded and cost-effective on the market of transport services.
\end{abstract}

\section{Introduction}

An extensive transport network connecting regions located both at small and significant distances from each other helps to ensure the smooth functioning of all interconnected economic systems, and also plays one of the main roles in the development of modern infrastructure potential. Regions that are in a more advantageous position in relation to the availability of resources and sales markets, as a rule, have a higher level of economic and, as a result, infrastructure development, which is also confirmed by the main priorities of the Transport Strategy of the Russian Federation for the period up to 2030 that include the increase of the competitiveness of national transport, the development of freight and passenger traffic, as well as strengthening of the innovative, social and environmental focus of the transport industry development. However, at present, not all regions ensure uniform development of the transport complex. These problems to a decisive extent depend on the activation of the potential of all types of transport based on the principles of realizing their competitive advantages and multimodality [1].

The high importance of the transport system and its infrastructure is due to the needs of the country's modern economy, which also finds support in the mechanism of the new system of public administration adopted in Russia in 2018-national projects [2]. However, this system was implemented in practice for the first time and faced a number of problems associated with systemic management failures, including the need to introduce "manual control"; inconsistency of actions of different levels of power structures; lack of project offices and new organizational links responsible for the vertical of interaction [3]; problems of entrepreneurship development associated with its low level, as well as with a high level of corruption; problems of the motivational component, i. e., the level of remuneration of performers for the implementation of such projects does not directly depend on the final result of the implementation of national projects; lack of sufficient elaborated information support for both performers and potential consumers of services (population); low quality of planning in the formation of a system of indicators for programs and projects [4]; problems of legislative support. It should be noted here that at present, on the territory of the Russian Federation, each subject has its own regulatory documents governing the implementation of transport projects, taking into account the peculiarities of regional executive bodies of state power [5]. However, at the state level, there are also

\footnotetext{
Corresponding author:borodulinasa@gumrf.ru
} 
many mechanisms that regulate the selection of certain transport projects that fall under the criteria for the implementation of development programs. Thus, the lack of a single method for assessing and selecting transport infrastructure projects leads to the spontaneity of their creation in the absence of consistency in terms of the development of transport infrastructure in the country. These problems give rise to an increasing number of refusals to create projects at various stages due to lack of funding, change of political courses, re-qualification of projects into image-building ones and vice versa, etc.

Considering the above, the issue of streamlining the existing system for assessing and selecting projects for the development of transport infrastructure in the absence of a single method at all levels is relevant at the present stage of transport development on the territory of the Russian Federation.

\section{Materials and Methods}

Carrying out research on the scientific elaboration of the problems associated with the assessment and selection of transport infrastructure development projects allowed concluding that by now the theoretical foundations of the economic assessment of transport infrastructure development projects have been sufficiently well covered in the scientific literature. The transport system is presented as a set of workers, vehicles and equipment, elements of transport infrastructure and infrastructure of transportation entities, including a management system aimed at the efficient movement of goods and passengers. Also, a transport system is understood as a set of technical base, organizational structure and personnel designed to meet transportation needs. In other words, many authors refer to the transport system as transport infrastructure and transport enterprises, as well as rolling stock and transport management in general. However, in our opinion, the concept of a transport system is as broad as possible and should include all aspects from rolling stock to transport management processes, as well as issues of financing the industry.

In terms of an "infrastructure project" is understood by Clifford F. Gray and Eric W. Larsen [6], the concept of a project is "a complex, unique, one-time event, limited by time, budget, resources and clear instructions for implementation, tailored to the needs of the customer". According to V.I. Liberzon [7], the project is a "temporary enterprise designed to create unique products and services". These concepts are united by the fact that the project is temporary and unique, however, in these definitions there is no fact of the life cycle of the project, and the project as such is not always a unique creation of something (from the point of view of creation, it is unique, from the point of view of providing services it is often not).

In our opinion, the most complete concept of a "project" and, as a consequence, an "infrastructure project" was proposed by a group of authors Mazur I.I., Shapiro V.D., Olderogge N.G.: purposeful predeveloped and planned creation or modernization of physical objects or technological processes, technical and organizational documentation for them, material, financial, labor and other resources, as well as management decisions and measures for their implementation".

The concept of "transport infrastructure" is presented in the works of I.F. Chernyavsky, B.A. Raizberg, L.G. Serebryakov, V.V. Yanovsky. [8] as "a set of economic entities (industries, enterprises and organizations)" and "types of activities" that provide and/or create conditions for the functioning of branches of material production (transport), the life of society or the solution of specific problems. In the studies of Ponomareva N.N. [9] transport infrastructure is an object of economic and geographical research, that is, without interrupting international economic integration. In our opinion, transport infrastructure should be understood not only as a system that includes objects, subjects and modes of transport, but also relations that arise in the process of interaction of system participants, which can be transformed and modified under the influence of external circumstances (change in the number of participants, for instance, drop out from the project; change of the form of project implementation, legal entities, etc.).

Taking into account the implementation of National Projects and the rapid development of the construction of new infrastructure projects in the field of transport on the territory of the Russian Federation, the emergence of a single functioning system for managing these projects along the entire vertical (state-regional-municipal) is required, which would take into account the interests of participants at each level of management, proposed would have an adequate methodological toolkit and be able to assess and select projects for the development of transport infrastructure that can quickly and efficiently achieve the set goals for the development of transport infrastructure, positively influence related industries and generate a low level of risk.

The issue of improving existing methods for assessing and selecting transport infrastructure development projects (TIDP) is due to the need to create an orderly system and a single method applicable at all levels that would reduce the number of unrealizable projects, allow selecting projects as objectively, comprehensively and transparently as possible, and also would be of practical relevance.

Currently, the most common methods of project evaluation include the following: the "price-quality" method, which allows determining the optimal ratio of the cost and quality of a project throughout its life/use cycle to meet the needs of end users [10]; the method of "comparative public sector costs" which includes a comparison of the possibilities of project implementation or with the help of public funding [11], the "CostBenefit" method with the possibility of assessing the aggregate long-term effect based on bringing the net benefits indicator at the discount rate to the current moment [12], methods associated with the analysis of costs (including efficiency, weighted efficiency, utility) [13]. Most of the methods involve the calculation of financial indicators of projects and do not consider their assessment from the point of view of compliance with the goals of socio-economic development, as well as the 
generation of social, environmental, informational, political and other effects. Such methods enable accurate determination of the economic efficiency of the project, but disallow evaluating the project in a complex and comprehensive manner. Among the author's methods developed in the theory, the method of I.N. Makarov should be noted [14], based on calculating the effectiveness of the project from various positions: the state (budget), investor (business), and analysis of social effectiveness. Within the framework of this method, the analysis of social efficiency is based on the position of the volume and quality of the goods produced and associated externalities; however, the adjacent effects from the impact of the project on other industries are not considered. We also studied economic and mathematical methods based on linear models (the model of Dean, Albach, Hax and Weingartner) [15], the main disadvantages of which are complexity, laboriousness in calculations; methods of linear programming (methods of Pareto, Borda, BOFF method), the main disadvantages of which are many options as a result of selection, the impossibility of taking into account the qualitative characteristics of projects; nonlinear models the main disadvantage of which is the difficulty in calculations. Experimental analytical methods [16] associated with expert assessments, such as the method of analyzing hierarchies, analytical networks, etc., were also considered.

Having analyzed the advantages and disadvantages of these methods, the authors concluded that the lack of a single integrated method of project evaluation and selection makes it impossible to build an orderly system for project implementation and impedes the uniform development of transport infrastructure, which gives rise to shortcomings in the project management system: there is no single coordination center, as a result of which each region chooses its own policy instruments in the field of transport. The methods used for assessing and selecting projects for the development of transport infrastructure do not take into account their specifics, as well as the issues of goal setting and the specifics of interaction with related industries [17]. Therefore, our proposed method of multi-criteria assessment and selection was developed taking into account the indicated disadvantages. The structural diagram of the method for assessing and selecting the TIDP is shown in Figure 1.

\begin{tabular}{|c|c|c|c|c|}
\hline \multirow{3}{*}{$\begin{array}{l}\text { 1. Selection of projects } \\
\text { using the hierarchy } \\
\text { analysis method based } \\
\text { on goal-setting criteria }\end{array}$} & \multicolumn{4}{|c|}{ Multitude of TIDPs } \\
\hline & State-level TIDPs & \multicolumn{2}{|c|}{ Region-level TIDPs } & Municipal-level TIDPs \\
\hline & Issues of state-level TIDPs & \multicolumn{2}{|c|}{$\begin{array}{c}\text { Issues of region-level } \\
\text { TIDPs }\end{array}$} & $\begin{array}{l}\text { Issues of municipal -level } \\
\text { TIDPs } \\
\end{array}$ \\
\hline & $\begin{array}{c}\text { Indicators of state-level } \\
\text { TIDPs }\end{array}$ & \multicolumn{2}{|c|}{$\begin{array}{l}\text { Indicators of region-level } \\
\text { TIDPs }\end{array}$} & $\begin{array}{l}\text { Indicators of municipal - } \\
\text { level TIDPs }\end{array}$ \\
\hline & $\begin{array}{c}\text { Determination of priority } \\
\text { state-level TIDPs }\end{array}$ & \multicolumn{2}{|c|}{$\begin{array}{l}\text { Determination of priority } \\
\text { region-level TIDPs }\end{array}$} & $\begin{array}{l}\text { Determination of priority } \\
\text { municipal -level TIDPs }\end{array}$ \\
\hline \multirow[t]{2}{*}{$\begin{array}{l}\text { 2. Comprehensive } \\
\text { efficiency assessment } \\
\text { by blocks }\end{array}$} & $\begin{array}{l}\text { Calculation of values } \\
\text { for the block of } \\
\text { economic indicators } \\
\text { TIDPs (E) }\end{array}$ & $\begin{array}{l}\text { Calculation of values } \\
\text { for the block of social } \\
\text { indicators TIDPs (S) }\end{array}$ & $\begin{array}{l}\text { Calculation of values } \\
\text { for the block of safe } \\
\text { environment indicators } \\
\text { TIDPs (Eco) }\end{array}$ & $\begin{array}{l}\text { Calculation of values } \\
\text { for the block of risk } \\
\text { assessment of TIDPs } \\
\text { (Q) }\end{array}$ \\
\hline & \multicolumn{4}{|c|}{ Calculation of complex efficiency (EF) } \\
\hline $\begin{array}{l}\text { 3. Drawing up a plan- } \\
\text { schedule for the } \\
\text { implementation of } \\
\text { projects }\end{array}$ & \multicolumn{4}{|c|}{$\begin{array}{l}\text { The first to be realized is the TIDP with the maximum value of the EF, } \\
\text { further projects are implemented in descending order }\end{array}$} \\
\hline
\end{tabular}

Figure 1. Block diagram of the method of multi-criteria assessment and selection of transport infrastructure development projects

The method proposed in the article includes three main stages: selection of projects by the method of hierarchy analysis. It was decided to use this method to ensure a balance of indicators that have different goals for the implementation of projects. Based on the results of carrying out and evaluating projects using the hierarchy analysis method [18], a priority project for implementation is determined for each group. The projects are distributed into groups in accordance of projects with the main defined goals. At each level (state, regional, municipal), the authors have identified the main goals for the achievement of which projects 
will be implemented within the framework of the following goals:

1. Development of infrastructure potential;

2. Improving the connectivity of territories; (ITS);

3. Development of intelligent transport systems

4. Provision of social services;

5. Provision of commercial services;

6. Spatial development of territories.

The goals are determined on the basis of the analysis of the ongoing TIDPs, planned TIDPs and the results of the analysis of problems in the transport sector that need to be addressed.

Further, a comparative assessment of priority projects is planned according to indicators that determine the level of social, economic, environmental status of the selected projects and the level of risks. The comparison of projects takes place in terms of indicators of social and commercial efficiency, environmental development, level of risks (for example, tax deductions, the project's contribution to the development of tourism, business development zones, its impact on the environment, etc.). For the convenience of making a comparative assessment, the indicators are conditionally divided into several blocks:

block of economic indicators (E);

block of social indicators $(\mathrm{S})$;

block of indicators related to environmental impact (Eco);

risk assessment block $(\mathrm{Q})$.

Within each block, it is planned to carry out a calculation based on a set of indicators presented in Table 1.

Table 1. Indicators for assessing TIDPs

\begin{tabular}{|c|c|}
\hline Block name & Indicator name \\
\hline $\begin{array}{l}\text { Block of economic } \\
\text { indicators }(\mathrm{E})\end{array}$ & $\begin{array}{l}\text { p 1.1. Discounted payback period of the project; } \\
\text { p 1.2. Payback period of the project; } \\
\text { p 1.3. Return on Investment Index; } \\
\text { p 1.4. Internal rate of return; }\end{array}$ \\
\hline $\begin{array}{lll}\text { Block of } & \text { social } \\
\text { indicators }(\mathrm{S}) & \end{array}$ & $\begin{array}{l}\text { p 2.1. Change in the share of the employed working-age population; } \\
\text { p 2.2. Change in the share of travel and business correspondence; } \\
\text { p 2.3. Change in the share of public transport in the total passenger turnover of transport; } \\
\text { p 2.4. Change in the proportion of fatal accidents per } 1000 \text { passengers; } \\
\text { p 2.5. Increase in the level of development of adjacent territories (calculated using point values, taking into } \\
\text { account indicators: the presence of communication with other territories, tourist and business purposes, the } \\
\text { integration of the project into the urban environment, an increase in the value of land and real estate in the } \\
\text { adjacent territories). }\end{array}$ \\
\hline $\begin{array}{l}\text { Block of indicators } \\
\text { related } \\
\text { environmental impact } \\
(\text { Eco) }\end{array}$ & $\begin{array}{l}\text { p 3.1. Change in the share of potential damage to the environment from the implementation of the TIDP } \\
\text { (point estimate: emission of toxic substances into the atmosphere during fuel combustion and fuel } \\
\text { evaporation, thermal radiation from running engines, electromagnetic radiation (strength of electric and } \\
\text { magnetic fields), vibroacoustic impact on the environment and humans); } \\
\text { p 3.2. Change in the share of vehicles using alternative energy sources. }\end{array}$ \\
\hline Risk assessment $(\mathrm{Q})$ & p 4.1. Risk Indicator of TIDP non-Implementation (q) \\
\hline Total estimate & $\begin{array}{l}\qquad E F=\sqrt[n]{\sum_{k=1}^{i 1} p(E) k * \sum_{m=1}^{i 2} p(S) m * \sum_{l=1}^{i 3} p(E c o) l * q} \\
\text { where } \mathrm{k}(\mathrm{k}=1 \ldots \mathrm{i} 1) ; \mathrm{m}(\mathrm{m}=1 \ldots \mathrm{i} 2) ; 1(\mathrm{l}=1 \ldots \mathrm{i} 3) \text { is the number of indicators } \mathrm{p} \text { in the blocks under } \\
\text { consideration; } \\
\mathrm{q} \text { is assessment of the risk of TIDP non-implementation; } \\
\mathrm{n} \text { is the number of parameters included in the calculation. }\end{array}$ \\
\hline
\end{tabular}

Next, a schedule is drawn up for the implementation of the TIDP, which will determine the priority project that will be implemented in the first place. A high-risk TIDP will be first directed for revision aimed at minimizing the risk, and then accepted for implementation within the framework of the schedule.

When new projects appear, they are evaluated according to the presented algorithm. Thus, the priority of projects in groups can change when new projects are introduced into the selection procedure. The process of adjusting the TIDP schedules should take place on an ongoing basis. The research results made it possible to describe the algorithm for assessing and selecting projects for the development of transport infrastructure (Figure 2) at different levels of industry management: state, regional and municipal. The development of the algorithm will enhance the practical significance of the proposed method. 


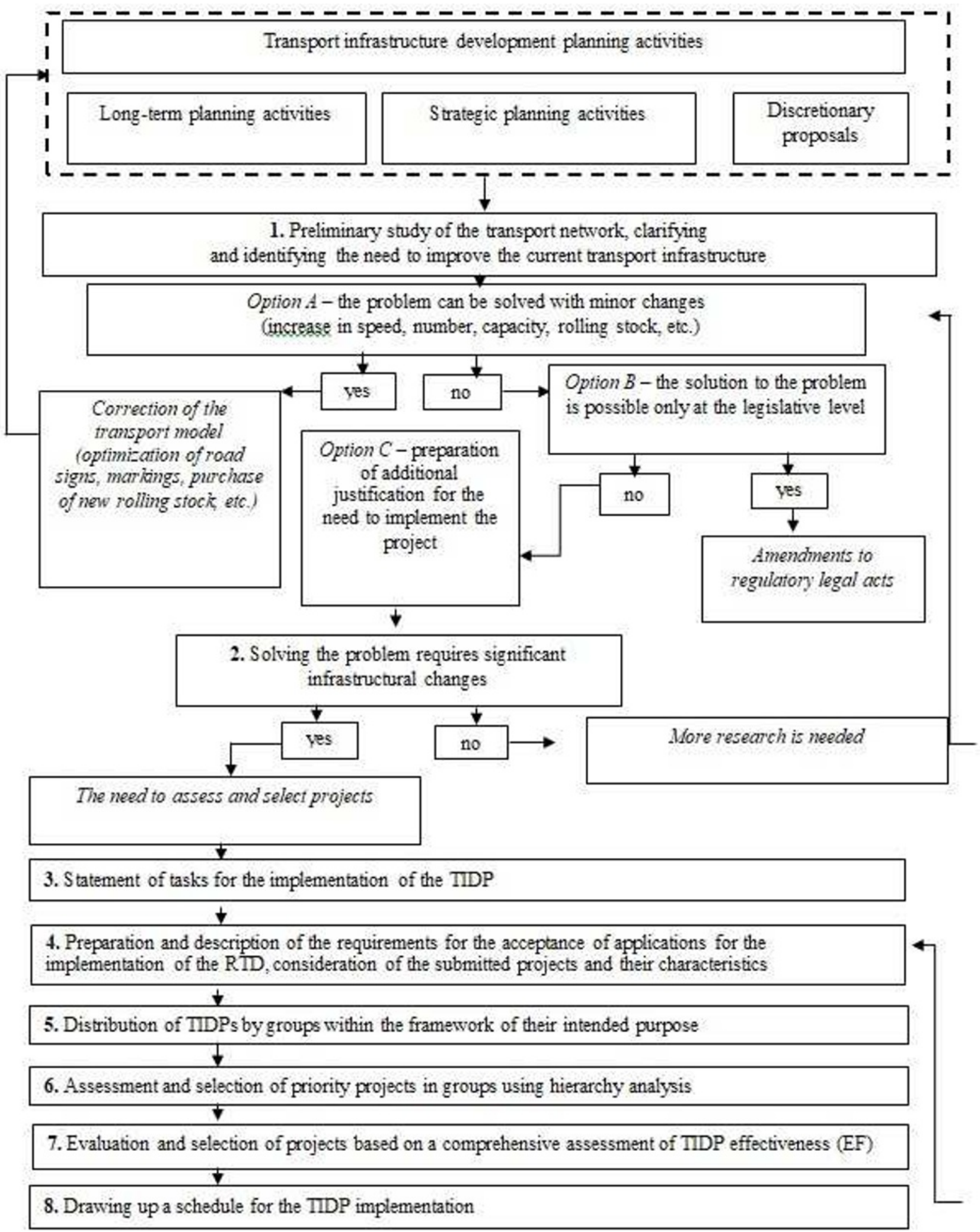

Figure 2. Decision-making algorithm for the assessment and selection of transport infrastructure development projects 


\section{Results and discussion}

On the basis of the developed method and the presented algorithm, the authors have tested the procedure for selecting projects planned for implementation on the territory of St. Petersburg (regional TIDP).

According to the data provided by the ROSINFA platform, as well as the information of the Committee for Transport and the Committee for Investments of St. Petersburg, at present, it is planned to implement 9 PRTIs and 2 projects are in prospective development. According to the proposed method, these projects are divided into three groups in accordance with the purpose and indicators: the group of projects "Improving the connectivity of territories", "Provision of social services", "Spatial development of territories". Further, the assessment and selection were carried out in accordance with the developed method. For instance, at the first stage of selection using the method of hierarchy analysis the priority projects were: Project No. 3 Construction of the highway; Project No. 10 Construction of a new river station; Project No. 5 Construction of a multi-storey garage.

During the second stage of selection, block calculations were made. The results are shown in Table 2.

Table 2. Results of calculations for projects at the second stage of assessment and selection.

\begin{tabular}{|c|c|c|c|c|}
\hline Indicators & Weigh & Project 3 & Project 5 & Project 10 \\
\hline \multicolumn{5}{|c|}{ Block E } \\
\hline $\begin{array}{l}\text { 1.1. Discounted payback period of the project }(\mathrm{p} \\
1.1) \text {; }\end{array}$ & 0.25 & 0 & 0.295 & 0.25 \\
\hline 1.2. Payback period of the project (p 1.2); & 0.25 & 0.549 & 0.278 & 0.25 \\
\hline 1.3. Return on Investment Index (p 1.3); & 0.25 & 0.23 & 3.977 & 0.21 \\
\hline 1.4. Internal rate of return ( $\mathrm{p} \mathrm{1.4).}$ & 0.25 & 0.177 & 0.245 & 0.21 \\
\hline TOTAL for block E: & & 0.956 & 4.795 & 0.92 \\
\hline \multicolumn{5}{|c|}{ Block S } \\
\hline $\begin{array}{l}\text { 2.1. Change in the share of the employed working- } \\
\text { age population from the implementation of the TIDP } \\
\text { (p 2.1) }\end{array}$ & 0.2 & 0 & 0.002 & 0.009 \\
\hline $\begin{array}{l}\text { 2.2. Change in the share of tourist and business } \\
\text { correspondence from the sale of the TIDP ( } 2.2)\end{array}$ & 0.2 & 0.03 & 0 & 0.044 \\
\hline $\begin{array}{l}\text { 2.3. Change in the share of urban public transport in } \\
\text { the general mode of transport from the } \\
\text { implementation of the TIDP }(\mathrm{p} 2.3)\end{array}$ & 0.2 & 0 & 0 & 0 \\
\hline $\begin{array}{l}\text { 2.4. Change in the share of annual fatal accidents } \\
* 10^{3} \text { (p 2.4) }\end{array}$ & 0.2 & $4 \%$ & $1 \%$ & 0 \\
\hline $\begin{array}{l}\text { 2.5. Changes in the level of development of adjacent } \\
\text { territories ( } 1 \text { 2.5) }\end{array}$ & 0.2 & 0.8 & 0.6 & 1.4 \\
\hline TOTAL for block S: & & 0.830 & 0.602 & 1.45 \\
\hline \multicolumn{5}{|c|}{ Block Eco } \\
\hline $\begin{array}{l}\text { 3.1. Cumulative potential damage to the } \\
\text { environment and humans ( } \mathrm{p} 3.1 \text {.) }\end{array}$ & 0.5 & 2.5 & 1.5 & 0.5 \\
\hline $\begin{array}{l}\text { 3.2. Change in the share of vehicles using alternative } \\
\text { energy sources (p 3.2.) }\end{array}$ & 0.5 & 0 & 0 & 0 \\
\hline TOTAL for block: & & 5.5 & 6.5 & 7.5 \\
\hline \multicolumn{5}{|c|}{ Block «Q» } \\
\hline $\begin{array}{l}\text { 4.1. Indicator of risk of non-realization of TIDP ( } p \\
4.1)\end{array}$ & 1 & 0.453 & 0.22 & 0.600 \\
\hline TOTAL for block: & & 0.453 & 0.22 & 0.600 \\
\hline Final Project Estimate (EF) & & $\begin{array}{c}\sqrt[4]{0.956} * 0.830 * 5.5 * 0,453 \\
\quad=\sqrt[4]{1.98}=1.19\end{array}$ & $\begin{array}{l}\sqrt[4]{4.13}= \\
1,43\end{array}$ & $\sqrt[4]{\mathbf{6 . 0}}=1,57$ \\
\hline
\end{tabular}


Calculations showed that the highest final calculated value was noted for Project 10 .

However, in the course of the research on this project, a high degree of risk of its non-implementation was revealed. Thus, this project needs to be finalized from the point of view of minimizing the risk and then proceed to implementation.

As a result, the following implementation schedule was drawn up: 1. Project 5 and 2. Project 3. Project 10 was sent for revision and was not implemented in the current circumstances.

\section{Conclusions}

It should be noted that the method developed in the article has a number of advantages, namely:

1. Comprehensiveness and completeness of the approach to the assessment and selection of TIDPs. The method involves the selection of projects according to the parameters of achieving the goal of developing transport infrastructure and efficiency.

2. Versatility. The method can be applied to any projects at all levels of management in the industry: state, regional, municipal.

3. The interests of the regions were taken into account. Dividing the TIDPs into groups will allow taking into account the interests of each subject and will ensure the uniform development of transport infrastructure in the territory of the Russian Federation.

4. The impact on related industries is taken into account. The possibility of considering the impact of the TIDPs on related industries and activities-tourism, trade, spatial development, economic activity of the population-will make it possible to assess the benefits of projects for the development of the region and the country as a whole.

5. Systematization. The multicriteria and phased assessment and selection excludes the possibility of choosing random TIDPs and streamlines the selection system.

6. Continuity. When new projects are received, it allows evaluating and selecting projects on an ongoing basis.

7. Practical applicability. The versatility of the method makes it possible for its practical implementation on the basis of existing executive bodies of state power to improve the mechanisms for evaluating and selecting projects.

According to the authors, the development of the study in the future should be directed to an in-depth analysis and detailing of the structure of the effects obtained from the implementation of large infrastructure projects in the transport sector, taking into account the influence of external factors, the development of foreign economic activity and the expansion of the country's transit potential.

\section{References}

1. M.I. Malyshev, Scientific Bulletin of MSTU GA, 4 (23), 2020. DOI 10.26467/2079-0619-2020-23-458-71.

2. O.B. Ivanov, E.M. Buchwald, ETAP: economic theory, analysis, practice, (2019). DOI 10.24411/2071-6435-2019-10067

3. S. V. Zapolsky, A. M. Andreeva Federalism. 1, 81-98, (2020). DOI 10.21686/2073-1051-2020-1$81-98$

4. A.V. Fedotov, K.V. Lebedev, A.A. Kovalenko, A.O. Polushkina, University management: practice and analysis. 24 (1), 28-43, (2020). DOI 10.15826/umpa.2020.01.002

5. S. Borodulina, T. Pantina, Model of sustainable economic development in the context of inland water transport management. Springer. Cham. 806-819. (2020), DOI: https://doi.org/10.1007/978-3-030-57450-5_68

6. N.V. Nemova, Education and Science. 6 (95), (2012). DOI 10.17853/1994-5639-2012-6-43-65

7. A. V. Zelentsova, Austrian journal of the humanities and social sciences, AJH 5-6, 159162, (2015). DOI https://doi.org/10.29013/AJH15-5.6-159-162

8. V. Yanovskiy, D. Slesarev Public Policy and Administration, 13(1), 9-21, (2014) DOI: http://dx.doi.org/10.5755/j01.ppaa.13.1.6761

9. N.N. Ponomareva Science for Education Today. 7(2), (2017). DOI: 10.15293/2226-3365.1702.06

10. D. Morallos, A. Amekudzi, The State of the Practice of Value for Money Analysis in Comparing Public Private Partnerships to Traditional Procurements: Public Works Management \& Policy. (2008). https://doi.org/10.1177/1087724X08326176

11. K. Ismail, R. Takim, A. H. Nawawi, Asian Social Science, $\quad 8 \quad$ (7), https://doi.org/doi:10.5539/ass.v8n7p192

12. D. Grimsey, M. K. Lewis, International Journal of Project Management, 20 (2), 107-118, (2002). https://doi.org/10.1016/S0263-7863(00)00040-5

13. S. Hui, Z. Ying, F. Zhi-qing, 2010 International Conference on Logistics Systems and Intelligent Management (ICLSIM). (2010). https://doi.org/10.1109/ICLSIM.2010.5461363

14. I.N. Makarov, Public-private partnership. 1(1), 37-50, (2014). doi: 10.18334/ppp.1.1.26

15. Z.A. Usmanov, Scientific. conf. Problems of management, processing and transmission of information" (UOPI-2017). Saratov, 658-659, 2017. DOI10.24143/2072-9502-2019-3-64-7.

16. A.M. Pokrovsky, V.G. Shumetov Internet magazine "Science" 7 (2), 18 p. DOI https://dx.doi.org/10.15862/87EVN215

17. T.A. Pantina, S.A. Borodulina, Review of European Studies, 7(9), 83-96, (2015). Doi: 10.5539/res.v7n9p83

18. M.Yu. Volokobinsky, O.A. Pekarskaya, D.A. Razi, Finance: Theory and Practice. 20 (2), 33- 
42, (2016). https://doi.org/10.26794/2587-5671-

2016-20-2-33-42 